OPEN ACCESS

Edited by: Hamid Morjani,

Université de Reims ChampagneArdenne, France

Reviewed by:

Raheleh Roudi,

University of Minnesota, United States Antonella Zannetti, Institute of Biostructure and

Bioimaging (CNR), Italy Alexander Pedroza-Gonzalez, National Autonomous University of Mexico, Mexico

*Correspondence: Zongliang Huang zonglianghuang@tongji.edu.cn Junjun Tang shtjj400@sina.com

Specialty section: This article was submitted to Molecular and Cellular Oncology, a section of the journal

Frontiers in Oncology

Received: 18 November 2021 Accepted: 19 January 2022 Published: 17 February 2022

Citation:

Jing Y, Liang W, Zhang L, Tang $J$ and Huang $Z$ (2022)

The Role of Mesenchymal Stem Cells in the Induction of Cancer-Stem Cell Phenotype.

Front. Oncol. 12:817971. doi: 10.3389/fonc.2022.817971

\section{The Role of Mesenchymal Stem Cells in the Induction of Cancer-Stem Cell Phenotype}

\author{
Yuanming Jing ${ }^{1}$, Wenqing Liang ${ }^{2}$, Lin Zhang ${ }^{3}$, Junjun Tang $^{4 *}$ and Zongliang Huang ${ }^{4}$ \\ 1 Department of Gastrointestinal Surgery, Shaoxing People's Hospital (Shaoxing Hospital, Zhejiang University School of \\ Medicine), Shaoxing, China, ${ }^{2}$ Department of Orthopaedics, Zhoushan Hospital of Traditional Chinese Medicine Affiliated to \\ Zhejiang Chinese Medical University, Zhoushan, China, ${ }^{3}$ Department of Pharmacy, Shaoxing People's Hospital, Shaoxing \\ Hospital, Zhejiang University School of Medicine, Shaoxing, China, ${ }^{4}$ Department of Radiology, Tongji Hospital, School of \\ Medicine, Tongji University, Shanghai, China
}

Cancer stem cells (CSCs) modify and form their microenvironment by recruiting and activating specific cell types such as mesenchymal stem cells (MSCs). Tumor-infiltrating MSCs help to establish a suitable tumor microenvironment for the restoration of CSCs and tumor progression. In addition, crosstalk between cancer cells and MSCs in the microenvironment induces a CSC phenotype in cancer cells. Many mechanisms are involved in crosstalk between CSCs/cancer cells and MSCs including cell-cell interaction, secretion of exosomes, and paracrine secretion of several molecules including inflammatory mediators, cytokines, and growth factors. Since this crosstalk may contribute to drug resistance, metastasis, and tumor growth, it is suggested that blockade of the crosstalk between MSCs and CSCs/cancer cells can provide a new avenue to improving the cancer therapeutic tools. In this review, we will discuss the role of MSCs in the induction of cancer stem cell phenotype and the restoration of CSCs. We also discuss targeting the crosstalk between MSCs and CSCs/cancer cells as a therapeutic strategy.

Keywords: mesenchymal stem cells, cancer stem cells, cytokines, exosomes, tumor microenvironment

\section{INTRODUCTION}

Cancer stem cells (CSCs), which have been shown to play a vital role in tumor origin, are considered to be responsible for tumor progression, drug resistance, and metastasis (1). CSCs can form their microenvironment by recruiting and activating specific cell types such as mesenchymal stem cells (MSCs). Then, MSCs can modify the stroma and establish a unique tissue microenvironment that is suitable for the restoration of CSCs and tumor progression (2). In addition, crosstalk between cancer cells and MSCs in the microenvironment can induce a CSC phenotype in cancer cells. Many mechanisms are involved in crosstalk between tumor cells and MSCs including cell-cell interaction, secretion of exosomes, and paracrine secretion of several molecules including inflammatory mediators, cytokines, and growth factors (3). Since crosstalk between tumor cells and MSCs may contribute to drug resistance, metastasis, and tumor growth, it is suggested that blockade of the crosstalk between MSCs and tumor cells can provide a new avenue to improving the cancer therapeutic tools. 
Many studies show the crosstalk between tumor cells and MSCs. For instance, transforming growth factor (TGF)- $\beta$ stimulated MSCs can induce a metastatic phenotype by upregulating Jagged-1, a major ligand of Notch signaling, in tumor cells (4). Indeed, activation of the Notch signaling pathway induces epithelial-mesenchymal transition (EMT) and promotes a cancer stem cell phenotype. This phenomenon is supported by other studies that show the relationship between the EMT process and CSCs (5). In another study, in hepatocellular carcinoma, treating MSCs with tumor necrosis factor- $\alpha$ (TNF- $\alpha)$ and interferon $\gamma$ (IFN $\gamma)$ causes an increase in production of TGF $\beta$ by MSCs which in turn could promote tumor metastasis by inducing EMT in cancer cells (6). Luo, et al. have reported that the increased metastatic phenotype of prostate cancer ( $\mathrm{PCa}$ ) cells could be due to an increase in the PCa stem cell population. They showed that increase in the stem cell population is mediated by MSCs through alteration of the CCL5-AR signaling pathway (7). Indeed, the upregulation of CCL5 in bone marrow mesenchymal stem cells (BM-MSCs) and PCa cells, after MSCs infiltrated into PCa microenvironment, lead to downregulation of the androgen receptor (AR) signaling pathway (7). Increasing in the PCa stem cell populations led to the upregulation of CXCR4, ZEB-1, matrix metallopeptidase 9 (MMP-9), and CD133 that these molecules promote the metastatic phenotype of PCa cells (7). Recently, Hossain et al. reported that in glioblastomas, tumor-associated mesenchymal stromal cells promote the proliferative and tumorigenic phenotype of glioma cancer stem cells (gCSCs) through the IL-6/STAT3 signaling pathway (8). The aggressiveness of gCSCs is enhanced in co-culture with MSCs, and these observations were supported by reduced survival in orthotopic xenograft mouse models, increased cell counts in vitro, enhanced angiogenesis, and tumor size in vivo (9). Gene expression analysis of cancer-associated (CA)-MSCs revealed that they can alter synthesis levels of bone morphogenetic protein (BMP) signaling pathway proteins. BMP2 can significantly increase the number of CSCs in primary ovarian tumor cells and ovarian cancer cell lines (10). In vivo and in vitro suppression of the BMP signaling pathway with Noggin suppress the capability of CA-MSCs to support tumor growth and tumor stemness (10). Thus, MSCs can enhance tumorigenesis, at least in part, through the promotion of the BMP signaling pathway (10). On the other hand, Vulcano et al. reported that Wharton's jelly of umbilical cord (WJMSC) exert, both in vivo and in vitro, conflicting impacts on lung cancer stem cells derived from various lung cancer subtypes (11).

In this review, we will discuss the role of MSCs in the induction of cancer stem cell phenotype and the restoration of CSCs. We also discuss targeting the crosstalk between MSCs and $\mathrm{CSCs} /$ cancer cells as a therapeutic strategy.

\section{MSCS MEDIATED MECHANISMS OF INCREASING CSC POPULATION}

Various mechanisms are involved in inducing the stem cell phenotype in tumor cells and restoring of CSCs including cell fusion, direct transformation of MSCs into CSCs, crosstalk of
MSCs with CSCs/tumor cells mediated by secretory factors, exosomes, etc. We will go into the details of the mentioned mechanisms in the following.

\subsection{MSCs Secreted Factors/Cancer Cell Contact and CSCs}

Plenty of studies has been performed to indicate how cellular components of the cancer microenvironment participate in cancer development. CSCs by recruiting and activating specific cell types establish their microenvironment. MSCs are one of the main cellular components which release various cytokines that have both autocrine and paracrine functions in the cancer milieu (2).

\subsubsection{MSCs Secreted Factors/Cancer Cell Contact and Induction of CSC Phenotype}

MSCs promote EMT by the secretion of cytokines and growth factors such as TGF $\beta$ (Figure 1). These factors stimulate transcriptional regulators, such as Zeb1, Twist, Slug, Snail, and others which are related to EMT $(12,13)$. For instance, in hepatocellular carcinoma, treatment of MSCs with IFN $\gamma$ and TNF $\alpha$ leads to a high expression level of TGF $\beta$ which in turn induces EMT-related properties in tumor cells (6). In another study, TGF $\beta$-induced MSCs in pancreatic cancer increase the metastatic potential by upregulating Jagged-1, a major ligand of Notch signaling in cancer cells (4). In turn, stimulation of the Notch signaling pathway promotes EMT and induces a CSC phenotype. Some other studies supported the role of EMT in the induction of CSC phenotype (5). An alternative mechanism of MSCinduced CSC phenotype has been indicated in gastric cancer. MSCs are recruited by gastric mucosal cells infected with Helicobacter which then transform into gastric cells expressing epithelial biomarkers including TFF2 and KRT1-19. Therefore, chronic inflammation induces the CSC properties of gastric cancer by inducing the EMT and metastatic phenotype (14).

The MSC-induced paracrine effect of TGF- $\beta 1$ and autocrine effects of WNT5A on the restoration of $\mathrm{CD} 133^{+} \mathrm{CSC}$ populations show the importance of the tumor microenvironment for the maintenance of CSCs (15), as illustrated in Figure 2. The autocrine effects of WNT5A in gastric carcinoma cells can contribute to the activation of the WNT- $\beta$-catenin signaling pathway (15). It has been shown that both TGF- $\beta$ and WNT5A play a crucial role in the stimulation of EMT in tumor cells: WNT5A stable melanoma cells transfectants indicate a spindle shape accompanied by increased vimentin expression and decreased Ecadherin expression (16), and TGF-beta mediated EMT is regulated by the SNAIL1-SMAD3/4 transcriptional complex, which acts as a suppressor of E-cadherin expression (17). Indeed, WNT5A and TGF- $\beta$ significantly enhance the expression of the Snail-family transcription factors, including Slug, Snail, Twist1, and Twist2 (15). These studies suggest a direct relationship between the EMT and the gain of CSC phenotype (18).

\subsubsection{MSCs Secreted IL-1, IL-6, PEG-2, and Induction of CSCs}

It has been shown that IL-1 released by head and neck squamous cell carcinoma (HNSCC) cells stimulates prostaglandin-E2 (PGE-2) from fibroblasts (19), as illustrated in Figure 3. It has been also 


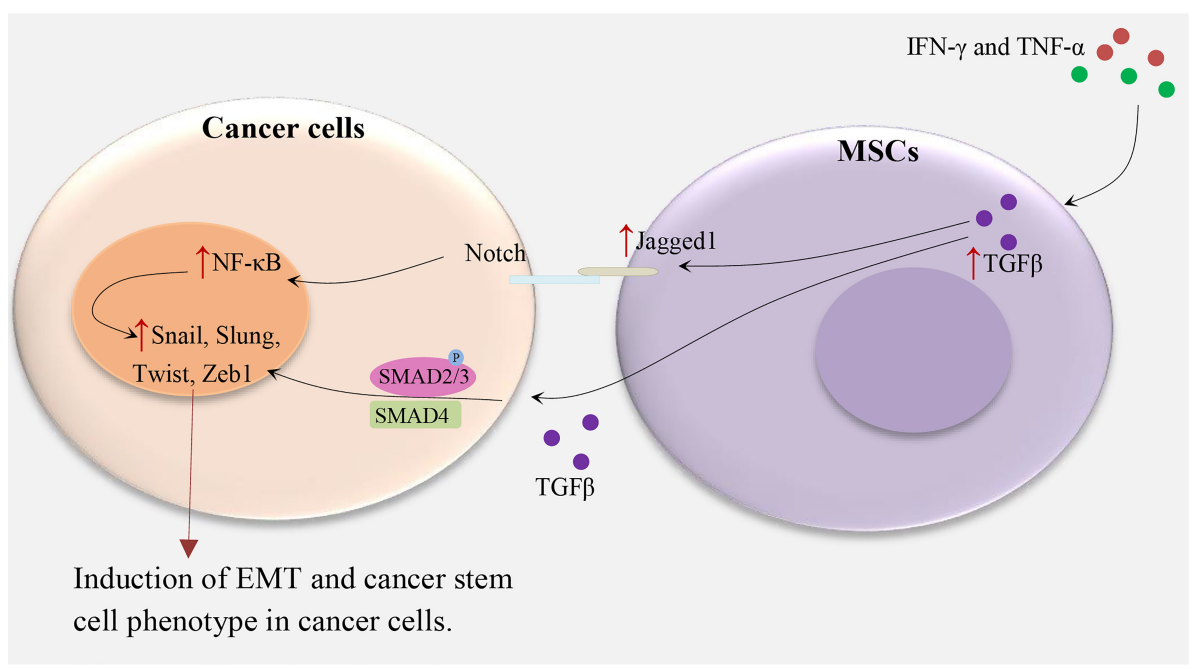

FIGURE 1 | MSCs and induction of CSC phenotype in cancer cells. IFN- $\gamma$ and TNF- $\alpha$ lead to TGF $\beta$ overexpression in MSCs, subsequently, TGF $\beta$ upregulates Notch signaling and TGF- $\beta /$ Smad signaling pathways in cancer cells and induce the cancer stem cell phenotype by upregulating Zeb1, Twist, Slug, Snail, and others which are related to $\operatorname{EMT}(4,6,12,13)$.

FIGURE 2 | Cell-cell contact and restoration of CSC populations. Cell contact between MSCs and cancer cells leads to an increase of TGF- $\beta 1$ in MSCs and WNT5A in cancer cells, subsequently, the paracrine effect of TGF- $\beta 1$ and autocrine effects of WNT5A on cancer cells result in the restoration of CSC populations. WNT5A and TGF- $\beta$ enhance the expression of the Snail-family transcription factors, including Slug, Snail, Twist1, and Twist2 (15-17).

reported that cancer cells are able to provoke a strong stimulation of the cyclooxygenase-2 (COX-2)/microsomal Prostaglandin-E synthase-1 (mPGES-1)/PGE 2 axis in MSCs recruited to the cancer-associated stroma by releasing IL-1 (20). The tumorpromoting effects of COX-2 are mostly related to its role in inducing PGE-2, which has pleiotropic effects on invasiveness, angiogenesis, motility, survival, and cell proliferation (21). It is found that IL-1 plays a critical role in the cancer cell-induced COX2/mPGES1/PGDH/PGE 2 response in MSCs that is necessary for tumor development (20). In colorectal cancer, MSCs release PGE-2 in response to IL- 1 secreted by tumor cells, PGE- 2 in an autocrine fashion promotes the expression of IL-8, IL-6, CXCL1, RANTES, and GRO- $\alpha$, which together stimulate the formation of CSCs (20). PGE-2, which can trigger the EMT phenotype, promote both the 




FIGURE 3 | Cytokine networks between MSCs and cancer cells and induction of CSC phenotype. Cancer cells stimulate the COX-2/mPGES-1/PGE 2 axis in MSCs by releasing IL-1. MSCs release PGE-2 in response to IL-1, PGE-2 in an autocrine fashion promote the expression of IL-8, IL-6, CXCL1, RANTES, and GRO- $\alpha$, which together stimulate the formation of CSCs (19-21).

frequency of cancer initiation and the number of CSCs (20). Li et al. (20) showed the partial EMT phenotype induced by PGE 2 suffices to increase CSCs by inducing a stem cell-like phenotype in cancer cells by suppressing cell-cell junctions without stimulating mesenchymal traits (20). Previous studies have shown the role of prostaglandin E2 in increasing the number of $\mathrm{CD} 44^{+}$cancer cells $(22,23)$. Observations show that other MSC-derived cytokines, compared to PEG-2, have marginal effects on the increasing tumorinitiating cell frequency (20). The PGE-2 and cytokines act in a paracrine fashion on the tumor cells to stimulate the $\beta$-catenin signaling pathway and formation of CSCs. Therefore, MSCs and derived cell types construct a CSC niche and promote cancer progression via the secretion of PGE-2 and other cytokines (20). IL-1 blocking therapies are used in the clinic to control inflammatory and infectious diseases and have a remarkable safety record (24). IL-1 blocking may provide a promising alternative to COX-2 inhibitors in cancer therapy (20).

It has been indicated the association between serum IL-6 levels and poor clinical outcomes of breast cancer patients (25, 26). IL-6 acts as a direct regulator of CSC self-renewal, a process triggered by the IL- 6 receptor/GP130 complex through the activation of STAT3 (27). On the other hand, It has been reported that MSCs can secrete IL-6 (28, 29), and induce tumor growth through the paracrine function (30). Liu et al. (31) indicated that the communication between CSCs and MSCs is facilitated by a positive feedback cytokine loop in which CXCL7 and IL6 play essential roles (31), as illustrated in Figure 3. This loop needs the simultaneous presence of these cells but does not require direct interactions between cell surfaces as indicated by trans-well and conditioned medium experiments (31). IL6 secreted by tumor cells interacts with gp130 and interleukin 6 receptor (IL-6R) on ALDEFLUOR-positive mesenchymal cells (MCs) and can promote the homing of
MSCs to the tumor sites, as well as stimulate CXCL7 expression by these cells. Then, MSC-derived CXCL7 interacts with tumor cells through the CXCR2 receptor (32), where it stimulates the production of some cytokines, such as IL-8 and IL-6 (32). IL-6 secreted by tumor cells interacts with MSCs and further enhances their CXCL7 expression, therefore generate a positive feedback loop. This cytokine loops between BCSCs and MSCs promote the self-renewal of BCSCs (31). Moreover, it has been shown that CXCL7 transfection increases the invasive ability of cancer cells (33), consistent with the previous findings that showed an increase in metastatic and invasive properties of CSCs (34). Furthermore, Sethi et al. indicated that IL-6-mediated Jagged1/Notch signaling induces breast cancer bone metastasis (35). These findings introduce IL-6 and its receptor as attractive therapeutic targets. It has been shown that CXCR1, a receptor for IL-8, and IL-8 can induce their selfrenewal (36). In addition, it has been reported that the interaction of IL-8 with the CXCR1 (highly expressed on breast cancer stem cells), on CSCs increases their invasive and self-renewal properties $(36,37)$. Blocking the CXCR1 in mouse xenograft models significantly decreases the number of BCSCs, leading to reduced metastasis and tumorigenicity.

\subsubsection{Crosstalk Between CSCs and MSCs Mediated by Exosomes}

The crosstalk between stromal cells and CSCs are facilitated by cell-cell interaction and paracrine factors (2). In addition, cellular crosstalk has also been reported to be facilitated by the secretion of extracellular vesicles (EVs) that can transfer nucleic acids, lipids, and proteins and are able to induce epigenetic changes in target cells (38-40). This EV-mediated crosstalk is associated with chemoresistance, tumor development, and the capacity of evading from immune surveillance (41-44). Numerous studies 
have shown that cancer EVs are not limited only to the cancer microenvironment but there are also in body fluids such as blood circulation, emphasizing the idea that these vesicles can also influence the cells in other tissues (45-48). Peinado et al. indicated that exosomes secreted by melanoma can "educated" bone marrow progenitor cells to promote metastatic phenotype (49). Stem cells likely can alter the expression of genes in neighboring cells through exosomes containing microRNAs (miRNAs) (50).

It has been shown that stimulated MSCs with CSC-derived EVs considerably increase the migratory ability in response to cancer chemo-attractive stimuli. Indeed, CSC-EVs increase the expression of migration process-related genes. CXCR4, which is increased after CSC-EV stimulation, enhances the migratory capacity of MSCs toward the tumor site through an SDF-1 concentration gradient secreted by cancer cells (51-53). Stimulated MSCs also show an increased CXCR7 expression, an SDF-1 receptor associated with paracrine actions of MSCs $(51,54,55)$. The ability of MSCs to modify extracellular matrix within the cancer microenvironment has been confirmed by increased expression of $M M P 1,2$, and 3 after stimulation with CSC-EVs. MMPs are proteolytic enzymes that are associated with metastasis processes, invasion, tumor growth, and angiogenesis (56). Tumor matrix remodeling activity of stimulated MSCs has also been confirmed by the increase of COL4A3 gene expression (51). This gene is involved in regulating cell adhesion, migration, and metastasis in various cancer types (57-59). EVs secreted from CSC rather than total cancer cell population show a central role in inducing pro-tumorigenic phenotype in MSCs (51).

Upon stimulation with CSC-EVs, the secretory profile of MSCs is changed and expression of IL-8, myeloperoxidase (MPO), and osteopontin (OPN) are increased (51). MPO has been shown to be involved in oxidative stress response and the anti-apoptotic process by converting nitric oxide (NO) into NO (+) that induces an S-nitrosylation of caspase-3, inhibiting its activity $(60,61)$. In clear cell renal cell carcinoma, OPN by stimulating of $\mathrm{NF}-\mathrm{\kappa B}$ and protecting cells from apoptosis induces tumor development (62). OPN also shows an autocrine function on MSCs by stimulating extracellular signal-regulated kinase (ERK) and focal adhesion kinase (FAK) signaling pathways via $\beta 1$-integrin activation. This leads to the increase of MSCs motility and subsequently promotes the migration of MSC (63).

The anti-tumor activity of MSCs may depend on the type or even stage of cancer. Whereas naive MSCs may demonstrate an anticancer activity (64-66), indeed pre-conditioning of MSCs by cancer EVs may change their phenotype and function. Therefore, it is recommended that the secretion of cancer EVs be pharmacologically inhibited for preventing their unwanted effects before the administration of MSCs in cell-based cancer therapy approaches $(67,68)$. The phenotypic changes in MSCs mediated by CSC-derived EVs are maintained even after removal of stimulation, suggesting a persistent change in MSC phenotype (51).

\subsubsection{CAFs Originated From MSCs and Cancer Stemness}

Although the majority of tumor tissue cancer-associated fibroblasts (CAFs) may originate from resident stromal fibroblasts, but now many studies show that a significant percentage of CAFs in cancers are originated from BM-MSCs. For instance, MSCs in mouse models of gastric cancer, breast cancer, and PDAC, BM-MSCs are recruited to the cancer site where they differentiate into CAFs (69-71). It has been reported that in a gastric cancer model, about $20 \%$ of CAFs in tumor sites are derived from BM-MSCs which have been recruited into the tumor microenvironment in a TGF- $\beta$ and CXCL-12 dependent manner (72).

The pro-stemness abilities of CAFs are one of the main mechanisms that increase oncogenesis. A specific subpopulation of CAFs has been identified that are proficient in secreting pro-stemness paracrine factors (73-79), thereby supporting the stemness properties and the self-renewal of tumor resident CSCs or increasing the transformation of tumor cells into CSCs. When exposed to cytotoxic stress such as chemotherapy, CAFs are further stimulated to produce prostemness cytokines or obtain a senescence-like secretory phenotype and secrete large amounts of pro-stemness chemokines that increase cancer stemness and aggressiveness following cancer treatment $(80,81)$. Therefore, blockade of the crosstalk of CSCs/cancer cells with pro-stemness CAFs and MSCs may introduce a new tool to improving the clinical outcome of solid tumors.

\subsection{Cell Fusion and CSC-Like Phenotype}

It has been shown that the biological phenomenon of cell fusion plays an important role in several pathological and physiological processes $(82,83)$. Cell fusion of stromal cells with tumor cells has been confirmed in human tumors and animal models (8486). Studies have demonstrated that hybrid cells resulting from a spontaneous fusion between cancer cells and MSCs indicate metastatic, tumorigenic, and stem cell-like properties (87-89) and this phenomenon leads to nuclear reprogramming (90). In addition, the theory of cell fusion may clarify the origin of CSCs and the mechanism for cancer metastasis and carcinogenesis. $\mathrm{He}$ et al. (91) reported that cell fusion of gastric epithelial cells with MSCs promotes proliferation, migration, and invasion capabilities compared with the parental cells (91). The fusion of MSCs with HepG2 also promotes the malignant properties of in vivo metastasis models (92). In contrast, some findings demonstrate that the fusion of MSCs with esophageal carcinoma cells suppresses tumorigenicity (93). It has been also reported that the fusion of tumor cells with normal fibroblasts inhibits the tumorigenicity through cell cycle arrest effects (94). Similar results have been shown in cell fusion studies of stem cells and tumor cells $(93,95)$. The cell fusion hypothesis of the CSCs suggests that the fusion process may lead to the EMT of tumor cells and simultaneously promote the generation of CSCs (96). Zhang et al. demonstrated that fusion between MSCs and lung tumor cells may directly activate EMT of the hybrids, which promotes the invasion and migration properties (97). Meanwhile, the overexpression of stem cell surface markers (CD44 and CD133), and stem cell transcription factors (Kif4, Oct4, Sox2, Nanog, and Bmil) in hybrids, show that the hybrids may obtain CSC properties after cell fusion (97). Although the hybrids show stem cell-like properties, further studies are 
required to determine whether the hybrids are the origin of CSCs.

\subsection{Transformation of MSCs Into CSCs}

The origin of cancer-initiating cells or CSCs has not been clearly determined. CSCs may be derived either from dedifferentiated mature cells or from transformed somatic stem cells (98-104). It has been shown that specific methylation of tumor suppressor genes, HIC1 and RasF1A, in MSCs can lead to the transformation of MSCs into CSCs. When MSCs transform into CSCs, they can increase drug resistance and allow tumor recurrence after treatment cessation (105). Indeed, abnormal DNA methylation of RassF1A and HIC1 is involved in the transformation of MSCs to cancer-like stem cells. Concurrent methylation of RassF1A and $\mathrm{HIC1}$ has been reported in advanced ovarian cancer (106), and HIC1 demonstrates enhanced concordant hypermethylation with other genes in advanced myelodysplasia syndrome (107), suggesting that disruption of HIC1-associated networks may be critical for cancer initiation. Unlike RassF1A, which can be inactivated by either epigenetic or genetic mechanisms, suppression of the HIC1 gene is mainly caused by DNA methylation (108). Thus, specific methylation of HIC1 could predispose cells to tumor development. A subsequent epigenetic/genetic hit, such as RassF1A methylation, may then permit more efficient tumor progression. Concordant silencing of RassF1A and HIC1 may synergistically interrupt the p53 Pathway for apoptosis signaling and involve in the observed tumorigenic capability of MSCs. Teng et al. (105) showed that forced epigenetic silencing of RassF1A and HIC1 is adequate to induce malignant properties, including migration ability, enhanced colony formation, chemoresistance, loss of contact inhibition, and tumor formation in normal somatic stem cells (105). In addition, MSCs also reprogram toward CSCs, due to the aberrant changes of tumor microenvironments, which leads to the tumor development through the increased production of Oct4, Sox2, Nanog and the activation of Hedgehog, Wnt, Akt/mTOR, and NF-kB signaling pathways $(31,109-112)$. It has been reported that EWS-FLI-1 fusion protein modulates the expression of CSC signature proteins such as Oct4, Nanog, and Sox2 in MSCs that can reprogram these cells toward Ewing sarcoma CSCs (112). It has been also shown that MSCs cultured with cancer cell-soluble factors show a cancer stem cell-like state (113).

\section{CANCER TREATMENT BY TARGETING CSCs, MSCs, AND THEIR CROSSTALK}

MSCs help to establish a suitable tumor microenvironment for the restoration of CSCs and tumor progression, as well as crosstalk between cancer cells and MSCs in the microenvironment induces a CSC phenotype in cancer cells. Since this communication can contribute to drug resistance, metastasis, and tumor growth, it is suggested that blockade of the crosstalk between MSCs and CSCs/ cancer cells can provide a new avenue to improving the cancer therapeutic tools. Here, we discussed various strategies in targeting the crosstalk between MSCs and CSCs/cancer cells (Tables 1, 2).

\subsection{Chemotherapy-Educated MSCs and CSCs}

Exposure of MSCs to cytotoxic agents resulted in a physiological response in these cells that eventually supports chemoresistance by enriching the CSC population. It has been reported that MSCs are recruited in large numbers to the tumor site in response to gemcitabine treatment. Gemcitabine-exposed MSCs, which are located near CSCs and support the CSC niche, significantly increase the secretion of CXCL10, which in turn induces CSCs proliferation as they overexpress CXCR3, the CXCL10 receptor. These events ultimately lead to increased tumor growth and drug resistance (114). It has been also shown that in a mouse xenograft model of PDAC, the number of BM-MSCs significantly increases following gemcitabine therapy in the tumor stroma (114). These gemcitabine-educated MSCs present a positive regulatory effect on cancer stem cells through the STAT-3: CXCL-10: CXCR-3 paracrine signaling axis. Similarly, MSCs secrete IL-8, IL-6, IL-7, IGF, and EGF, which promote chemoresistance following hyperthermia or paclitaxel therapy $(127,128)$. It has been also reported that cisplatin-exposed MSCs release specific polyunsaturated fatty acids which in turn increase the regrowth of cancers following treatment (129). In addition, exposure with cisplatin changes phosphorylation of several tyrosine kinases, including c-Jun, WNK-1, p53, and STAT3 in MSCs, and promotes MSC survival and secretion of IL-8 and IL6. In turn, these events induce chemoresistance of cancer cells (130). However, the exact mechanisms by which MSCs promote chemoresistance have not been identified. Altogether, ample evidence emphasizes the central role of MSCs and CAFs in the expansion and maintenance of CSCs. Thus, targeting these cells may provide a new way to improve the clinical outcome of desmoplastic cancers.

\subsection{Targeting the Crosstalk Between MSCs and CSCs}

Due to the pro-tumorigenic activities of MSCs, a number of studies had been conducted to target MSCs as a therapeutic method in cancer (131). Because tumor-infiltrating MSCs can directly support cancer stem cells through several paracrine signaling pathways, including IL-7, IL-6, Jagged-1, PGE-2, CXCL-1, and CXCL-10 (4, 20, 114, 132), blockade of this paracrine communication between CSCs and MSCs may be potentially valuable in inhibiting tumor stemness in solid tumors. Indeed, a recent study has demonstrated the potential application of this approach (114). In a mouse model of PDAC, MSCs are located near CSCs, the CSC niche, following gemcitabine treatment. Gemcitabine-exposed MSCs release high levels of CXCL-10 that stimulate its receptor CXCR-3 on CSCs, triggering the STAT-3 signaling pathway and supporting the survival of CSCs (114). It has been reported that systemic injection of the CXCR3 antagonist (AMG487) with "nano-ghost (NG)", MSC-derived membrane-based nanoparticles, leads to its 
TABLE 1 | Targeting approaches of crosstalk between MSCs and CSCs.

\begin{tabular}{|c|c|c|}
\hline Targeting Approach & Molecular/Cellular Target & Description \\
\hline \multirow{5}{*}{$\begin{array}{l}\text { Targeting the molecular } \\
\text { crosstalk between cells }\end{array}$} & CXCR3 antagonist (AMG487) & Cytotoxic agent exposed MSCs secrete high levels of CXCL-10 that stimulate its receptor \\
\hline & with "nano-ghost (NG)" & CXCR-3 on CSCs, triggering STAT-3 signaling pathway and supporting the survival of CSCs \\
\hline & Blocking the IL-1 & $\begin{array}{l}\text { A promising alternative to COX-2 inhibitors in cancer therapy. IL-1 secreted by MSCs induce } \\
\text { the CSC phenotype }\end{array}$ \\
\hline & Blocking IL-6 and its receptor & $\begin{array}{l}\text { MSCs release the pro-stemness cytokine IL-6, the various STAT-3 inhibitors and/or anti-IL-6 } \\
\text { antibodies exploited to blockade the CAF/MSC-CSC crosstalk }\end{array}$ \\
\hline & Blocking the CXCR1 & Blocking the CXCR1 significantly decreased the number of CSCs \\
\hline \multirow[t]{9}{*}{ Direct targeting of cells } & Targeting CAFs/MSCs & CAFs can account for more than $90 \%$ of the total cancer size. \\
\hline & & $\begin{array}{l}\text { CAFs are often localized to the margin of the glands or the cancer cell nests and close to } \\
\text { blood vessels, therefore, drug delivery to these cells is easy. }\end{array}$ \\
\hline & $\begin{array}{l}\text { Dual targeting of CAFs and } \\
\text { MSCs }\end{array}$ & $\begin{array}{l}\text { synergistic effect and maximize the anticancer efficacy in the treatment of desmoplastic } \\
\text { cancers. }\end{array}$ \\
\hline & Targeting pro-stemness & Because of the dynamic, heterogeneous, and plastic properties of CSCs, targeting the CAFs/ \\
\hline & CAFs/MSCs & MSCs is more reasonable than the direct targeting of CSCs. \\
\hline & & $\begin{array}{l}\text { Targeting the specific subpopulations of pro-stemness CAFs will provide more specific and } \\
\text { safer therapies than the non-specific targeting of CAFs }\end{array}$ \\
\hline & $\begin{array}{l}\text { Specifically targeting of CSCs } \\
\text { by TRAIL-expressing MSCs }\end{array}$ & TNF-related apoptosis-inducing ligand (TRAIL)-expressing MSCs specifically target CSCs \\
\hline & $\begin{array}{l}\text { Low-dose metronomic (LDM) } \\
\text { chemotherapy }\end{array}$ & $\begin{array}{l}\text { at least reduce chemotherapy-induced stimulation of MSCs and their production of pro- } \\
\text { stemness chemokines such as CXCL-10 }\end{array}$ \\
\hline & $\begin{array}{l}\text { Targeting the CSCs by using } \\
\text { the exosomes }\end{array}$ & Exosomes derived from MSCs containing exogenous LNA-antimiR-142-3p to inhibit miR-142 \\
\hline
\end{tabular}

Reference

$(36,74$ $115,116)$

$(122,123)$

TABLE 2 | Agents targeting CSC, MSC, and CSC-MSC crosstalk in clinical trials.

\begin{tabular}{|c|c|c|c|c|c|}
\hline Drug/agent Name & Drug Target & Cancer Type & Phase & Current Status & NCT Number \\
\hline \multicolumn{6}{|c|}{ Surface antigens of CSC } \\
\hline Removab & EpCAM/CD3 & Ovarian cancer & $\|$ & Completed & NCT00189345 \\
\hline Talacotuzumab & CD123 & Acute myeloid leukemia & $\|/\| \|$ & Completed & NCT02472145 \\
\hline Mylotarg & CD33 & CD33+ R/R AML & IV & Completed & NCT03727750 \\
\hline \multicolumn{6}{|c|}{ Immune checkpoints } \\
\hline Atezolizumab & PD-L1 & NSCLC & III & Completed & NCT02008227 \\
\hline Ipilimumab & CTLA-4 & NSCLC & $\|$ & Completed & NCT01820754 \\
\hline Varlilumab & CD27 & Advanced refractory solid tumors & $1 / \|$ & Completed & NCT02335918 \\
\hline \multicolumn{6}{|l|}{ Hedgehog inhibitors } \\
\hline Vismodegib & Smoothened & Metastatic colorectal cancer & $\|$ & Completed & NCT00636610 \\
\hline Sonidegib & Smoothened & Basal cell carcinoma syndrome & $\|$ & Completed & NCT01350115 \\
\hline \multicolumn{6}{|l|}{ Notch inhibitors } \\
\hline MK-0752 & $\gamma$-Secretase & Advanced or metastatic sarcoma & $|/| \mid$ & Completed & NCT01154452 \\
\hline Demcizumab & DLL4 & Metastatic pancreatic ductal adenocarcinoma & $\|$ & Completed & NCT02289898 \\
\hline \multicolumn{6}{|l|}{ Wnt inhibitors } \\
\hline Ipafricept & Wnt receptor & Solid tumors & । & Completed & NCT01608867 \\
\hline PRI-724 & $\beta$-Catenin/CBP & Acute myeloid leukemia & $|/| \mid$ & Completed & NCT01606579 \\
\hline \multicolumn{6}{|c|}{ Other signaling pathways inhibitors } \\
\hline Galunisertib & TGF- $\beta$ & Prostate cancer & $\|$ & Recruiting & NCT02452008 \\
\hline Ruxolitinib & JAK & Breast cancer & $\|$ & Completed & NCT01594216 \\
\hline \multicolumn{6}{|l|}{ Niche inhibitors } \\
\hline Plerixafor & CXCR4 & Multiple myeloma & $|/| \mid$ & Completed & NCT01010880 \\
\hline BL-8040 & CXCR4 & Metastatic pancreatic adenocarcinoma & $\|$ & Active, not recruiting & NCT02907099 \\
\hline \multicolumn{6}{|c|}{ CSC-directed immunotherapy } \\
\hline CD19 CAR-T & CD19+ cells & B cell leukemia and lymphoma & $|/| \mid$ & Recruiting & NCT03398967 \\
\hline MESO-19 CAR-T & & Metastatic pancreatic cancer & I & Terminated & NCT02465983 \\
\hline LeY-targeted CAR-T & & Myeloid malignancies & $|/| \mid$ & Unknown & NCT02958384 \\
\hline BCMA CAR-T & & Multiple myeloma & $|/| \mid$ & Recruiting & NCT03767751 \\
\hline \multicolumn{6}{|c|}{ MSCs-based cancer therapy } \\
\hline MSC & & Hematological malignancies & $\|$ & Terminated & NCT01045382 \\
\hline CELYVIR & & Metastatic and refractory tumors & $|/| \mid$ & Completed & NCT01844661 \\
\hline MSC-TRAIL & & Lung adenocarcinoma & $|/| \mid$ & Recruiting & NCT03298763 \\
\hline BM-MSCs-DNX2401 & & Glioma & 1 & Recruiting & NCT03896568 \\
\hline
\end{tabular}


accumulation in the CSC niche, thus decreasing the number of CSCs and enhancing the therapeutic efficacy of gemcitabine (114). The direct depletion of MSCs may be an alternative approach to preventing their communication with CSCs. However, the negative effects of the removal of MSCs on a person's health remain an open question. Alternatively, it has been shown that low-dose metronomic (LDM) gemcitabine therapy regimen can decrease therapy-induced secretion of pro-stemness factors from CAFs in PDAC (81). Therefore, it is likely that LDM chemotherapy may also at least reduce chemotherapy-induced stimulation of MSCs and their production of pro-stemness chemokines such as CXCL-10. This possibility needs further investigation. On the other hand, since MSCs release the pro-stemness cytokine IL-6 (20), the various STAT-3 inhibitors and/or anti-IL-6 antibodies are exploited to blockade the CAF/MSC-CSC crosstalk $(74,115$, $116,133)$. It is anticipated that dual targeting of CAFs and MSCs may have a synergistic effect and maximize the anticancer efficacy in the treatment of desmoplastic cancers (121). Targeting approaches of crosstalk between MSCs and CSCs are summarized in Tables 1, 2.

\subsection{Targeting Pro-Stemness CAFs and MSCs}

Unlike direct targeting of CSCs, which poses substantial challenges such as dynamic and plastic properties of CSCs, targeting the MSCs or CAFs along with the pro-stemness niches they create can have several advantages in cancer therapy. First and foremost, there is ample evidence to show that CSCs are very plastic and heterogeneous and the transformation between different CSC populations plays a key role in cancer development and treatment response (122). For example, breast cancer CSCs can transition between epitheliallike states and mesenchymal-like (134-136). CSCs can also be originated from differentiated tumor cells through transdifferentiation or cellular reprogramming (73), which can be facilitated by cytotoxic agents such as ionizing radiation and chemotherapy $(81,137)$. It has been shown that eradicating LGR $-5^{+}$CSCs suppresses tumor growth, whereas the regrowth of cancer occurs following the removal of the cell death inducers due to the regeneration of CSCs from differentiated cancer cells (137, 138). Unlike CSCs, CAFs are both phenotypically and genetically stable; thus, CAF-targeted treatments may result in a more stable anti-CSC effect compared with direct targeting of CSCs. Second, identification of specific subpopulations of prostemness CAFs will facilitate CAF-targeted therapy, and they not only render new therapeutic targets, such as GPR-77 (123) but also provide more specific and safer therapies than the nonspecific targeting of CAFs (139). In desmoplastic cancers such as pancreatic cancer, CAFs are present in large numbers in the stroma, which can account for more than $90 \%$ of the total cancer size $(118,119)$. Accordingly, MSC- or CAF-targeted therapies may be more effective than CSC-targeted therapy in desmoplastic cancers. Furthermore, CAFs are often localized to the margin of the glands or the cancer cell nests and close to blood vessels, therefore, drug delivery to these cells is easy (120).
By contrast, CSCs are located farther away from blood vessels in desmoplastic cancers. In fact, CAFs per se is a major barrier for the delivery of nanoparticles and drugs to tumor cells $(140,141)$. Indeed, studies have been shown the importance of the spatial distribution of cells in the treatment of desmoplastic cancers (142). Collectively, in the treatment of desmoplastic cancers, targeting the communication between MSCs or CAFs with CSCs is more reasonable, possible, and clinically promising than the direct targeting of CSCs (121).

\subsection{Specifically Targeting of CSCs by TRAIL-Expressing MSCs}

By genetic engineering of MSCs, specific cancer cells can be targeted. For instance, it has been shown that TNF-related apoptosis-inducing ligand (TRAIL)-expressing MSCs specifically target tumor cells in lung carcinoma, therefore reducing chemoresistance, cancer aggressiveness, and relapse (124). TRAIL is a member of the TNF ligand family that can cause apoptosis through the interaction of its death receptors. TRAIL selectively initiates apoptosis of a variety of cancer cells and transformed cells, but not most normal cells, and therefore it has attracted great interest as a promising factor in cancer therapy (143). Several studies have shown the ability of TRAIL-expressing MSCs homing to the tumor site (144-146). TRAIL is a protein that causes apoptosis of tumor cells, without injuring the normal cells, by binding to specific TRAIL receptors and stimulation of the extrinsic apoptosis pathway (147). The activation of the NF- $\kappa \mathrm{B}$ signaling pathway (148) and the overexpression of the TRAIL decoy receptors can contribute toward TRAIL resistance in normal cells (149). TRAIL-induced apoptosis has been shown in CD133-positive glioma cells (125). However, Capper et al. showed that CD133-positive neurosphere-forming glioma cells were completely resistant to TRAIL (150). It has been reported that TRAIL-expressing MSCs can target both stem-like, side population (SP) cells, and non-SP cells, and in combination with traditional chemotherapies show a synergistic effect in apoptosis induction (151). It has been also shown that physiological levels of TRAIL in MSC-EV was not effective in inducing apoptosis in NSCLC cells (152). High expression of death receptor 4 (DR4) and DR5 were observed in liver and lung cancer-derived CSCs, representing their contribution to CSCs TRAIL sensitivity $(153,154)$. Activation of both intrinsic and extrinsic apoptosis pathways through extracellular stimulation by TRAIL may induce further effects, especially for chemo-resistant CSCs that show resistance to intrinsic apoptosis pathways (155).

\subsection{Exosome-Based Cancer Therapy}

Numerous miRNAs are differentially expressed in CSCs, which can be used as potential targets in the treatment of cancer (156). It has been recently shown that upregulation of miR-150 and miR-142-3p in BCSCs compared to non-tumorigenic tumor cells can be related to clonogenicity and tumorigenicity of BCSCs (157). Thus, using complementary miR-142 inhibitors in BCSCs could reduce tumor growth. Exosomes derived from MSCs can act as an extracellular messenger to introduce exogenous LNA- 
antimiR-142-3p to breast cancer stem-like cells to inhibit miR142-3p and decrease the tumorigenicity, proliferation, and colony formation ability of the cancer stem-like cells (126). MSCs are one of the main sources of exosomes that are especially considered in clinical applications. Indeed, the biological activity of MSCs-derived exosomes is likely akin to the effects mediated by MSCs themselves. Thus, unlike MSCs, the exosomes can be exploited as cell-free carriers, which do not have a risk of tumorigenesis (158). Targeting the CSCs by using the exosomes can introduce a novel tool for destroying CSCs in anticancer therapies (126).

\subsection{CSCs Targeting by Immunotherapy}

Recently, immunotherapy has gained great attention in cancer treatment (159). Many studies have used immunotherapeutic approaches to target cancer stem cells. Immune checkpoint inhibitors, antibody-based and adoptive cell therapy approaches are used for CSCs targeting (Table 2). CAR-T cell therapy, as an adoptive cell therapy method, is used for CSC-directed immunotherapy by targeting CD20 (NCT03398967), CD123 (NCT02937103), CD19 (NCT03398967) positive cells. Various immune checkpoint blocking agents, such as CTLA-4 inhibitors (Ipilimumab that is approved by the FDA) (1) and PD1/PD-L1 inhibitors: atezolizumab (2), avelumab (3), cemiplimab (4), and nivolumab (5) are undergoing clinical trials. Targeting surface antigens of CSC, such as EpCAM/CD3 (NCT00189345), CD123 (NCT02472145), CD33 (NCT03727750) are other strategies in CSC-directed immunotherapy.

\subsection{The Clinical Challenges in MSC-Based Therapies}

Various factors affect the clinical outcome of MSCs-based therapies. One of the influencing factors is variables related to the preparation of the MSC product. Donor variations such as genetics, age, health status, gender can affect the potency of MSCs (160). In addition, MSCs tissue of origin (161), isolation methods (162), the culture conditions (163), cryopreservation, and thaw/culture rescue protocols $(164,165)$ causing additional variations in potency of MSCs. The administration of MSCs is another variable that can affect the residence time, viability, and homing of MSCs. This variable includes the following: the inoculation site (dense/non-dense tissue), administration route (local/systemic), injection/infusion buffer, injection device

\section{REFERENCES}

1. Frank NY, Schatton T, Frank MH. The Therapeutic Promise of the Cancer Stem Cell Concept. J Clin Invest (2010) 120:41-50. doi: 10.1172/JCI41004

2. Ye J, Wu D, Wu P, Chen Z, Huang J. The Cancer Stemcell Niche: Cross Talk Between Cancer Stemcells and Their Microenvironment. Tumor Biol (2014) 35:3945-51. doi: 10.1007/s13277-013-1561-x

3. Bhowmick NA, Moses HL. Tumor-Stroma Interactions. Curr Opin Genet Dev (2005) 15:97-101. doi: 10.1016/j.gde.2004.12.003

4. Kabashima-Niibe A, Higuchi H, Takaishi H, Masugi Y, Matsuzaki Y, Mabuchi Y, et al. Mesenchymal Stem Cells Regulate EpithelialMesenchymal Transition and Tumor Progression of Pancreatic Cancer Cells. Cancer Sci (2013) 104:157-64. doi: 10.1111/cas.12059 features (needle size/geometry), and cell carrier materials (166, 167). MSC recipients are the third important variable that can affect the therapeutic outcome. Which can refer to the following: host cytotoxic responses against MSCs (168), and the host disease/severity which can lead to highly variable microenvironmental factors such as hypoxia, inflammation status, and ECM that influence the function of MSCs (169).

\section{CONCLUSIONS AND PERSPECTIVE}

MSCs can modify the stroma, and helping to establish a tissue microenvironment that favors the restoration of CSCs and tumor progression, as well as crosstalk between cancer cells and MSCs in the microenvironment, promotes a CSC phenotype in cancer cells. Since crosstalk between CSCs and MSCs promote drug resistance, mediates metastasis, and induces tumor growth by inducing CSC phenotype in cancer cells and restoration of CSCs, it is suggested that blockade of the crosstalk of MSCs with CSCs can provide a new avenue to improving the cancer therapeutic tools. Indeed, targeting the communication between MSCs with CSCs is more reasonable, possible, and clinically promising than the direct targeting of CSCs in the treatment of desmoplastic cancers.

\section{AUTHOR CONTRIBUTIONS}

Conception and design: $\mathrm{ZH}$, JT, and YJ. Collection and assembly of data: YJ, WL, and LZ. Manuscript writing: YJ, WL, LZ, and $\mathrm{ZH}$. Made critical revisions: WL, ZH, and JT. All authors reviewed and approved of the final manuscript.

\section{FUNDING}

This study was supported by the Public Welfare Application Plan Project of Shaoxing (2018C30109); Project of Shaoxing Medical Key Discipline Construction Plan (2019SZD06); Health and Family Planning Commission of Zhejiang province (2018KY831). The funder had no role in study design, data collection and analysis, decision to publish, or preparation of the manuscript.

5. Shibue T, Weinberg RA. EMT, CSCs, and Drug Resistance: The Mechanistic Link and Clinical Implications. Nat Rev Clin Oncol (2017) 14:611-29. doi: 10.1038/nrclinonc.2017.44

6. Jing Y, Han Z, Liu Y, Sun K, Zhang S, Jiang G, et al. Mesenchymal Stem Cells in Inflammation Microenvironment Accelerates Hepatocellular Carcinoma Metastasis by Inducing Epithelial-Mesenchymal Transition. PloS One (2012) 7:e43272. doi: 10.1371/journal.pone.0043272

7. Luo J, Ok Lee S, Liang L, Huang CK, Li L, Wen S, et al. Infiltrating Bone Marrow Mesenchymal Stem Cells Increase Prostate Cancer Stem Cell Population and Metastatic Ability via Secreting Cytokines to Suppress Androgen Receptor Signaling. Oncogene (2014) 33:2768-78. doi: 10.1038/onc.2013.233

8. Hossain A, Shinojima N, Gumin J, Feng G, Lang FF. Tumor-Associated Mesenchymal Stromal Cells Increase Proliferation and Maintain Stemness 
of Glioma Stem Cells Through the Il6/Stat3 Pathway. Neuro Oncol (2011) 13:19. doi: 10.1093/neuonc/nor148

9. Kong BH, Shin H, Kim SH, Mok HS, Shim JK, Lee JH, et al. Increased In Vivo Angiogenic Effect of Glioma Stromal Mesenchymal Stem-Like Cells on Glioma Cancer Stem Cells From Patients With Glioblastoma. Int J Oncol (2013) 42:1754-62. doi: 10.3892/ijo.2013.1856

10. McLean K, Gong Y, Choi Y, Deng N, Yang K, Bai S, et al. Human Ovarian Carcinoma-Associated Mesenchymal Stem Cells Regulate Cancer Stem Cells and Tumorigenesis via Altered BMP Production. J Clin Invest (2011) 121:3206-19. doi: 10.1172/JCI45273

11. Vulcano F, Milazzo L, Ciccarelli C, Eramo A, Sette G, Mauro A, et al. Wharton's Jelly Mesenchymal Stromal Cells Have Contrasting Effects on Proliferation and Phenotype of Cancer Stem Cells From Different Subtypes of Lung Cancer. Exp Cell Res (2016) 345:190-8. doi: 10.1016/j.yexcr.2016.06.003

12. Martin FT, Dwyer RM, Kelly J, Khan S, Murphy JM, Curran C, et al. Potential Role of Mesenchymal Stem Cells (MSCs) in the Breast Tumour Microenvironment: Stimulation of Epithelial to Mesenchymal Transition (EMT). Breast Cancer Res Treat (2010) 124:317-26. doi: 10.1007/s10549010-0734-1

13. Xue Z, Wu X, Chen X, Liu Y, Wang X, Wu K, et al. Mesenchymal Stem Cells Promote Epithelial to Mesenchymal Transition and Metastasis in Gastric Cancer Though Paracrine Cues and Close Physical Contact. J Cell Biochem (2015) 116:618-27. doi: $10.1002 / j c b .25013$

14. Houghton JM, Stoicov C, Nomura S, Rogers AB, Carlson J, Li H, et al. Gastric Cancer Originating From Bone Marrow-Derived Cells. Science (2004) 306:1568-71. doi: 10.1126/science.1099513

15. Nishimura K, Semba S, Aoyagi K, Sasaki H, Yokozaki H. Mesenchymal Stem Cells Provide an Advantageous Tumor Microenvironment for the Restoration of Cancer Stem Cells. Pathobiology (2012) 79:290-306. doi: $10.1159 / 000337296$

16. Dissanayake SK, Wade M, Johnson CE, O'Connell MP, Leotlela PD, French $\mathrm{AD}$, et al. The Wnt5A/protein Kinase C Pathway Mediates Motility in Melanoma Cells via the Inhibition of Metastasis Suppressors and Initiation of an Epithelial to Mesenchymal Transition. J Biol Chem (2007) 282:1725971. doi: $10.1074 /$ jbc.M700075200

17. Vincent T, Neve EPA, Johnson JR, Kukalev A, Rojo F, Albanell J, et al. A SNAIL1-SMAD3/4 Transcriptional Repressor Complex Promotes TGF- $\beta$ Mediated Epithelial-Mesenchymal Transition. Nat Cell Biol (2009) 11:94350. doi: $10.1038 /$ ncb1905

18. Mani SA, Guo W, Liao MJ, Eaton EN, Ayyanan A, Zhou AY, et al. The Epithelial-Mesenchymal Transition Generates Cells With Properties of Stem Cells. Cell (2008) 133:704-15. doi: 10.1016/j.cell.2008.03.027

19. Alcolea S, Antón R, Camacho M, Soler M, Alfranca A, Avilés-Jurado FX, et al. Interaction Between Head and Neck Squamous Cell Carcinoma Cells and Fibroblasts in the Biosynthesis of PGE 2. J Lipid Res (2012) 53:630-42. doi: 10.1194/jlr.M019695

20. Li HJ, Reinhardt F, Herschman HR, Weinberg RA. Cancer-Stimulated Mesenchymal Stem Cells Create a Carcinoma Stem Cell Niche via Prostaglandin E2 Signaling. Cancer Discov (2012) 2:840-55. doi: 10.1158/ 2159-8290.CD-12-0101

21. Wang D, Dubois RN. Eicosanoids and Cancer. Nat Rev Cancer (2010) 10:181-93. doi: 10.1038/nrc2809

22. Rudnick JA, Arendt LM, Klebba I, Hinds JW, Iyer V, Gupta PB, et al. Functional Heterogeneity of Breast Fibroblasts Is Defined by a Prostaglandin Secretory Phenotype That Promotes Expansion of Cancer-Stem Like Cells. PloS One (2011) 6:e24605. doi: 10.1371/journal.pone.0024605

23. Ishimoto T, Oshima H, Oshima M, Kai K, Torii R, Masuko T, et al. CD44+ Slow-Cycling Tumor Cell Expansion Is Triggered by Cooperative Actions of Wnt and Prostaglandin E2 in Gastric Tumorigenesis. Cancer Sci (2010) 101:673-8. doi: 10.1111/j.1349-7006.2009.01430.x

24. Dinarello CA. Why Not Treat Human Cancer With Interleukin-1 Blockade? Cancer Metastasis Rev (2010) 29:317-29. doi: 10.1007/s10555-010-9229-0

25. Ravishankaran P, Karunanithi R. Clinical Significance of Preoperative Serum Interleukin-6 and C-Reactive Protein Level in Breast Cancer Patients. World J Surg Oncol (2011) 9:18. doi: 10.1186/1477-7819-9-18

26. Zhang G-J, Adachi I. Serum Interleukin-6 Levels Correlate to Tumor Progression and Prognosis in Metastatic Breast Carcinoma. Anticancer Res (1999) 19:1427-32.

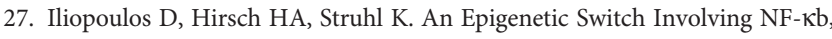
Lin28, Let-7 MicroRNA, and IL6 Links Inflammation to Cell Transformation. Cell (2009) 139:693-706. doi: 10.1016/j.cell.2009.10.014

28. Gunn WG, Conley A, Deininger L, Olson SD, Prockop DJ, Gregory CA. A Crosstalk Between Myeloma Cells and Marrow Stromal Cells Stimulates Production of DKK1 and Interleukin-6: A Potential Role in the Development of Lytic Bone Disease and Tumor Progression in Multiple Myeloma. Stem Cells (2006) 24:986-91. doi: 10.1634/stemcells.2005-0220

29. Arnulf B, Lecourt S, Soulier J, Ternaux B, Lacassagne MN, Crinquette A, et al. Phenotypic and Functional Characterization of Bone Marrow Mesenchymal Stem Cells Derived From Patients With Multiple Myeloma. Leukemia (2007) 21:158-63. doi: 10.1038/sj.leu.2404466

30. Spaeth EL, Dembinski JL, Sasser AK, Watson K, Klopp A, Hall B, et al. Mesenchymal Stem Cell Transition to Tumor-Associated Fibroblasts Contributes to Fibrovascular Network Expansion and Tumor Progression. PloS One (2009) 4:e4992. doi: 10.1371/journal.pone.0004992

31. Liu S, Ginestier C, Ou SJ, Clouthier SG, Patel SH, Monville F, et al. Breast Cancer Stem Cells are Regulated by Mesenchymal Stem Cells Through Cytokine Networks. Cancer Res (2011) 71:614-24. doi: 10.1158/00085472.CAN-10-0538

32. Kalwitz G, Endres M, Neumann K, Skriner K, Ringe J, Sezer O, et al. Gene Expression Profile of Adult Human Bone Marrow-Derived Mesenchymal Stem Cells Stimulated by the Chemokine CXCL7. Int J Biochem Cell Biol (2009) 41:649-58. doi: 10.1016/j.biocel.2008.07.011

33. Tang Z, Yu M, Miller F, Berk RS, Tromp G, Kosir MA. Increased Invasion Through Basement Membrane by CXCL7-Transfected Breast Cells. Am J Surg (2008) 196:690-6. doi: 10.1016/j.amjsurg.2008.08.001

34. Sheridan C, Kishimoto H, Fuchs RK, Mehrotra S, Bhat-Nakshatri P, Turner $\mathrm{CH}$, et al. CD44+/CD24-Breast Cancer Cells Exhibit Enhanced Invase Properties: An Early Step Necessary for Metastasis. Breast Cancer Res (2006) 8:R59. doi: 10.1186/bcr1610

35. Sethi N, Dai X, Winter CG, Kang Y. Tumor-Derived Jagged1 Promotes Osteolytic Bone Metastasis of Breast Cancer by Engaging Notch Signaling in Bone Cells. Cancer Cell (2011) 19:192-205. doi: 10.1016/j.ccr.2010.12.022

36. Ginestier C, Liu S, Diebel ME, Korkaya H, Luo M, Brown M, et al. CXCR1 Blockade Selectively Targets Human Breast Cancer Stem Cells In Vitro and in Xenografts. J Clin Invest (2010) 120:485-97. doi: 10.1172/JCI39397

37. Charafe-Jauffret E, Ginestier C, Iovino F, Wicinski J, Cervera N, Finetti P, et al. Breast Cancer Cell Lines Contain Functional Cancer Stem Sells With Metastatic Capacity and a Distinct Molecular Signature. Cancer Res (2009) 69:1302-13. doi: 10.1158/0008-5472.CAN-08-2741

38. Camussi G, C. Deregibus M, Tetta C. Tumor-Derived Microvesicles and the Cancer Microenvironment. Curr Mol Med (2012) 13:58-67. doi: 10.2174/ 156652413804486304

39. Ratajczak J, Wysoczynski M, Hayek F, Janowska-Wieczorek A, Ratajczak MZ. Membrane-Derived Microvesicles: Important and Underappreciated Mediators of Cell-to-Cell Communication. Leukemia (2006) 20:1487-95. doi: 10.1038/sj.leu.2404296

40. Vafaei S, Roudi R, Madjd Z, Aref AR, Ebrahimi M. Potential Theranostics of Circulating Tumor Cells and Tumor-Derived Exosomes Application in Colorectal Cancer. Cancer Cell Int (2020) 20:1-15. doi: 10.1186/s12935020-01389-3

41. Grange C, Tapparo M, Collino F, Vitillo L, Damasco C, Deregibus MC, et al. Microvesicles Released From Human Renal Cancer Stem Cells Stimulate Angiogenesis and Formation of Lung Premetastatic Niche. Cancer Res (2011) 71:5346-56. doi: 10.1158/0008-5472.CAN-11-0241

42. Al-Nedawi K, Meehan B, Rak J. Microvesicles: Messengers and Mediators of Tumor Progression. Cell Cycle (2009) 8:2014-8. doi: 10.4161/cc.8.13.8988

43. Lee TH, D’Asti E, Magnus N, Al-Nedawi K, Meehan B, Rak J. Microvesicles as Mediators of Intercellular Communication in Cancer-the Emerging Science of Cellular "Debris". Semin Immunopathol (2011) 33:455-67. doi: 10.1007/s00281-011-0250-3

44. Castellana D, Zobairi F, Martinez MC, Panaro MA, Mitolo V, Freyssinet JM, et al. Membrane Microvesicles as Actors in the Establishment of a Favorable Prostatic Tumoral Niche: A Role for Activated Fibroblasts and CX3CL1-CX3CR1 Axis. Cancer Res (2009) 69:785-93. doi: 10.1158/0008-5472.CAN-08-1946

45. Muturi HT, Dreesen JD, Nilewski E, Jastrow H, Giebel B, Ergun S, et al. Tumor and Endothelial Cell-Derived Microvesicles Carry Distinct 
CEACAMs and Influence T-Cell Behavior. PloS One (2013) 8:e74654. doi: 10.1371/journal.pone.0074654

46. Taylor DD, Gercel-Taylor C. MicroRNA Signatures of Tumor-Derived Exosomes as Diagnostic Biomarkers of Ovarian Cancer. Gynecol Oncol (2008) 110:13-21. doi: 10.1016/j.ygyno.2008.04.033

47. Salido-Guadarrama I, Romero-Cordoba S, Peralta-Zaragoza O, HidalgoMiranda A, Rodríguez-Dorantes M. MicroRNAs Transported by Exosomes in Body Fluids as Mediators of Intercellular Communication in Cancer. Onco Targets Ther (2014) 7:1327-38. doi: 10.2147/OTT.S61562

48. Li J, Sherman-Baust CA, Tsai-Turton M, Bristow RE, Roden RB, Morin PJ. Claudin-Containing Exosomes in the Peripheral Circulation of Women With Ovarian Cancer. BMC Cancer (2009) 9:244. doi: 10.1186/1471-2407-9244

49. Peinado H, Alečković M, Lavotshkin S, Matei I, Costa-Silva B, MorenoBueno G, et al. Melanoma Exosomes Educate Bone Marrow Progenitor Cells Toward a Pro-Metastatic Phenotype Through MET. Nat Med (2012) 18:883-91. doi: $10.1038 / \mathrm{nm} .2753$

50. Yuan A, Farber EL, Rapoport AL, Tejada D, Deniskin R, Akhmedov NB, et al. Transfer of microRNAs by Embryonic Stem Cell Microvesicles. PloS One (2009) 4:e4722. doi: 10.1371/journal.pone.0004722

51. Lindoso RS, Collino F, Camussi G. Extracellular Vesicles Derived From Renal Cancer Stem Cells Induce a Pro-Tumorigenic Phenotype in Mesenchymal Stromal Cells. Oncotarget (2015) 6:7959-69. doi: 10.18632/ oncotarget. 3503

52. Park SA, Ryu CH, Kim SM, Lim JY, Park SI, Jeong CH, et al. CXCR4Transfected Human Umbilical Cord Blood-Derived Mesenchymal Stem Cells Exhibit Enhanced Migratory Capacity Toward Gliomas. Int J Oncol (2011) 38:97-103. doi: 10.3892/ijo-00000828

53. Gao H, Priebe W, Glod J, Banerjee D. Activation of Signal Transducers and Activators of Transcription 3 and Focal Adhesion Kinase by Stromal CellDerived Factor 1 Is Required for Migration of Human Mesenchymal Stem Cells in Response to Tumor Cell-Conditioned Medium. Stem Cells (2009) 27:857-65. doi: 10.1002/stem.23

54. Liu H, Liu S, Li Y, Wang X, Xue W, Ge G, et al. The Role of SDF-1-CXCR4/ CXCR7 Axis in the Therapeutic Effects of Hypoxia-Preconditioned Mesenchymal Stem Cells for Renal Ischemia/Reperfusion Injury. PloS One (2012) 7:e34608. doi: 10.1371/journal.pone.0034608

55. Balabanian K, Lagane B, Infantino S, Chow KYC, Harriague J, Moepps B, et al. The Chemokine SDF-1/CXCL12 Binds to and Signals Through the Orphan Receptor RDC1 in T Lymphocytes. J Biol Chem (2005) 280:35760-6. doi: 10.1074/jbc.M508234200

56. Egeblad M, Werb Z. New Functions for the Matrix Metalloproteinases in Cancer Progression. Nat Rev Cancer (2002) 2:161-74. doi: 10.1038/nrc745

57. Nie XC, Wang JP, Zhu W, Xu XY, Xing YN, Yu M, et al. COL4A3 Expression Correlates With Pathogenesis, Pathologic Behaviors, and Prognosis of Gastric Carcinomas. Hum Pathol (2013) 44:77-86. doi: 10.1016/j.humpath.2011.10.028

58. Ando H, Aihara R, Ohno T, Ogata K, Mochiki E, Kuwano H. Prognostic Significance of the Expression of MUC1 and Collagen Type IV in Advanced Gastric Carcinoma. Br J Surg (2009) 96:901-9. doi: 10.1002/bjs.6635

59. Smrkolj Š, Eržen M, Rakar S. Prognostic Significance of Topoisomerase II Alpha and Collagen IV Immunoexpression in Cervical Cancer. Eur J Gynaecol Oncol (2010) 31:380-5.

60. Ortiz De Montellano PR. Catalytic Sites of Hemoprotein Peroxidases. Annu Rev Pharmacol Toxicol (1992) 32:89-107. doi: 10.1146/annurev.pa. 32.040192 .000513

61. Saed GM, Ali-Fehmi R, Jiang ZL, Fletcher NM, Diamond MP, Abu-Soud $\mathrm{HM}$, et al. Myeloperoxidase Serves as a Redox Switch That Regulates Apoptosis in Epithelial Ovarian Cancer. Gynecol Oncol (2010) 116:276-81. doi: 10.1016/j.ygyno.2009.11.004

62. Matušan-Ilijaš K, Damante G, Fabbro D, Dordević G, Hadžisejdić I, Grahovac M, et al. Osteopontin Expression Correlates With Nuclear Factor-אb Activation and Apoptosis Downregulation in Clear Cell Renal Cell Carcinoma. Pathol Res Pract (2011) 207:104-10. doi: 10.1016/ j.prp.2010.11.004

63. Zou C, Luo Q, Qin J, Shi Y, Yang L, Ju B, et al. Osteopontin Promotes Mesenchymal Stem Cell Migration and Lessens Cell Stiffness via Integrin $\beta 1$,
FAK, and ERK Pathways. Cell Biochem Biophys (2013) 65:455-62. doi: 10.1007/s12013-012-9449-8

64. Bruno S, Collino F, Iavello A, Camussi G. Effects of Mesenchymal Stromal Cell-Derived Extracellular Vesicles on Tumor Growth. Front Immunol (2014) 5:382. doi: 10.3389/fimmu.2014.00382

65. Bruno S, Collino F, Deregibus MC, Grange C, Tetta C, Camussi G. Microvesicles Derived From Human Bone Marrow Mesenchymal Stem Cells Inhibit Tumor Growth. Stem Cells Dev (2013) 22:758-71. doi: 10.1089/ scd.2012.0304

66. Khakoo AY, Pati S, Anderson SA, Reid W, Elshal MF, Rovira II, et al. Human Mesenchymal Stem Cells Exert Potent Antitumorigenic Effects in a Model of Kaposi's Sarcoma. J Exp Med (2006) 203:1235-47. doi: 10.1084/ jem.20051921

67. Wysoczynski M, Ratajczak MZ. Lung Cancer Secreted Microvesicles: Underappreciated Modulators of Microenvironment in Expanding Tumors. Int J Cancer (2009) 125:1595-603. doi: 10.1002/ijc.24479

68. Del Conde I, Shrimpton CN, Thiagarajan P, López JA. Tissue-FactorBearing Microvesicles Arise From Lipid Rafts and Fuse With Activated Platelets to Initiate Coagulation. Blood (2005) 106:1604-11. doi: 10.1182/ blood-2004-03-1095

69. Guo X, Oshima H, Kitmura T, Taketo MM, Oshima M. Stromal Fibroblasts Activated by Tumor Cells Promote Angiogenesis in Mouse Gastric Cancer. J Biol Chem (2008) 283:19864-71. doi: 10.1074/jbc.M800798200

70. Mishra PJ, Mishra PJ, Humeniuk R, Medina DJ, Alexe G, Mesirov JP, et al. Carcinoma-Associated Fibroblast-Like Differentiation of Human Mesenchymal Stem Cells. Cancer Res (2008) 68:4331-9. doi: 10.1158/ 0008-5472.CAN-08-0943

71. Beckermann BM, Kallifatidis G, Groth A, Frommhold D, Apel A, Mattern J, et al. VEGF Expression by Mesenchymal Stem Cells Contributes to Angiogenesis in Pancreatic Carcinoma. Br J Cancer (2008) 99:622-31. doi: 10.1038/sj.bjc.6604508

72. Quante M, Tu SP, Tomita H, Gonda T, Wang SSW, Takashi S, et al. Bone Marrow-Derived Myofibroblasts Contribute to the Mesenchymal Stem Cell Niche and Promote Tumor Growth. Cancer Cell (2011) 19:257-72. doi: 10.1016/j.ccr.2011.01.020

73. Iliopoulos D, Hirsch HA, Wang G, Struhl K. Inducible Formation of Breast Cancer Stem Cells and Their Dynamic Equilibrium With Non-Stem Cancer Cells via IL6 Secretion. Proc Natl Acad Sci USA (2011) 108:1397-402. doi: $10.1073 /$ pnas. 1018898108

74. Korkaya H, Kim G, Davis A, Malik F, Henry NL, Ithimakin S, et al. Activation of an IL6 Inflammatory Loop Mediates Trastuzumab Resistance in HER2+ Breast Cancer by Expanding the Cancer Stem Cell Population. Mol Cell (2012) 47:570-84. doi: 10.1016/j.molcel.2012.06.014

75. Korkaya H, Liu S, Wicha MS. Breast Cancer Stem Cells, Cytokine Networks, and the Tumor Microenvironment. J Clin Invest (2011) 121:3804-9. doi: 10.1172/JCI57099

76. Chen WJ, Ho CC, Chang YL, Chen HY, Lin CA, Ling TY, et al. CancerAssociated Fibroblasts Regulate the Plasticity of Lung Cancer Stemness via Paracrine Signalling. Nat Commun (2014) 5:1-17. doi: 10.1038/ ncomms 4472

77. Tsuyada A, Chow A, Wu J, Somlo G, Chu P, Loera S, et al. CCL2 Mediates Cross-Talk Between Cancer Cells and Stromal Fibroblasts That Regulates Breast Cancer Stem Cells. Cancer Res (2012) 72:2768-79. doi: 10.1158/00085472.CAN-11-3567

78. Lonardo E, Hermann PC, Mueller MT, Huber S, Balic A, Miranda-Lorenzo I, et al. Nodal/activin Signaling Drives Self-Renewal and Tumorigenicity of Pancreatic Cancer Stem Cells and Provides a Target for Combined Drug Therapy. Cell Stem Cell (2011) 9:433-46. doi: 10.1016/j.stem.2011.10.001

79. Shi Y, Gao W, Lytle NK, Huang P, Yuan X, Dann AM, et al. Targeting LIFMediated Paracrine Interaction for Pancreatic Cancer Therapy and Monitoring. Nature (2019) 569:131-5. doi: 10.1038/s41586-019-1130-6

80. Lotti F, Jarrar AM, Pai RK, Hitomi M, Lathia J, Mace A, et al. Chemotherapy Activates Cancer-Associated Fibroblasts to Maintain Colorectal CancerInitiating Cells by IL-17a. J Exp Med (2013) 210:2851-72. doi: 10.1084/ jem.20131195

81. Chan TS, Hsu CC, Pai VC, Liao WY, Huang SS, Tan KT, et al. Metronomic Chemotherapy Prevents Therapy-Induced Stromal Activation and 
Induction of Tumor-Initiating Cells. J Exp Med (2016) 213:2967-88. doi: $10.1084 /$ jem.20151665

82. Noubissi FK, Ogle BM. Cancer Cell Fusion: Mechanisms Slowly Unravel. Int J Mol Sci (2016) 17:1587. doi: 10.3390/ijms17091587

83. Ogle BM, Cascalho M, Platt JL. Biological Implications of Cell Fusion. Nat Rev Mol Cell Biol (2005) 6:567-75. doi: 10.1038/nrm1678

84. Li GC, Ye QH, Dong QZ, Ren N, Jia HL, Qin LX. Mesenchymal Stem Cells Seldomly Fuse With Hepatocellular Carcinoma Cells and Are Mainly Distributed in the Tumor Stroma in Mouse Models. Oncol Rep (2013) 29:713-9. doi: 10.3892/or.2012.2174

85. Pawelek JM. Cancer Cell Fusion With Migratory Bone Marrow-Derived Cells as an Explanation for Metastasis: New Therapeutic Paradigms. Futur Oncol (2008) 4:449-52. doi: 10.2217/14796694.4.4.449

86. Pawelek JM, Chakraborty AK. Fusion of Tumour Cells With Bone MarrowDerived Cells: A Unifying Explanation for Metastasis. Nat Rev Cancer (2008) 8:377-86. doi: $10.1038 / \mathrm{nrc} 2371$

87. Rappa G, Mercapide J, Lorico A. Spontaneous Formation of Tumorigenic Hybrids Between Breast Cancer and Multipotent Stromal Cells is a Source of Tumor Heterogeneity. Am J Pathol (2012) 180:2504-15. doi: 10.1016/ j.ajpath.2012.02.020

88. Dittmar T, Schwitalla S, Seidel J, Haverkampf S, Reith G, Meyer-Staeckling S, et al. Characterization of Hybrid Cells Derived From Spontaneous Fusion Events Between Breast Epithelial Cells Exhibiting Stem-Like Characteristics and Breast Cancer Cells. Clin Exp Metastasis (2011) 28:75-90. doi: 10.1007/ s10585-010-9359-3

89. Xu MH, Gao X, Luo D, Zhou XD, Xiong W, Liu GX. EMT and Acquisition of Stem Cell-Like Properties Are Involved in Spontaneous Formation of Tumorigenic Hybrids Between Lung Cancer and Bone Marrow-Derived Mesenchymal Stem Cells. PloS One (2014) 9:e87893. doi: 10.1371/ journal.pone. 0087893

90. Powell AE, Anderson EC, Davies PS, Silk AD, Pelz C, Impey S, et al. Fusion Between Intestinal Epithelial Cells and Macrophages in a Cancer Context Results in Nuclear Reprogramming. Cancer Res (2011) 71:1497-505. doi: 10.1158/0008-5472.CAN-10-3223

91. He X, Li B, Shao Y, Zhao N, Hsu Y, Zhang Z, et al. Cell Fusion Between Gastric Epithelial Cells and Mesenchymal Stem Cells Results in Epithelialto-Mesenchymal Transition and Malignant Transformation. BMC Cancer (2015) 15:1-11. doi: 10.1186/s12885-015-1027-1

92. Li H, Feng Z, Tsang TC, Tang T, Jia X, He X, et al. Fusion of HepG2 Cells With Mesenchymal Stem Cells Increases Cancer-Associated and Malignant Properties: An In Vivo Metastasis Model. Oncol Rep (2014) 32:539-47. doi: 10.3892/or.2014.3264

93. Wang Y, Fan H, Zhou B, Ju Z, Yu L, Guo L, et al. Fusion of Human Umbilical Cord Mesenchymal Stem Cells With Esophageal Carcinoma Cells Inhibits the Tumorigenicity of Esophageal Carcinoma Cells. Int J Oncol (2012) 40:370-7. doi: 10.3892/ijo.2011.1232

94. Harris H. The Analysis of Malignancy by Cell Fusion: The Position in 1988. Cancer Res (1986) 48:3302-6.

95. Schichor C, Albrecht V, Korte B, Buchner A, Riesenberg R, Mysliwietz J, et al. Mesenchymal Stem Cells and Glioma Cells Form a Structural as Well as a Functional Syncytium In Vitro. Exp Neurol (2012) 234:208-19. doi: 10.1016/j.expneurol.2011.12.033

96. Lu X, Kang Y. Cell Fusion Hypothesis of the Cancer Stem Cell. Adv Exp Med Biol (2011) 950:129-40. doi: 10.1007/978-94-007-0782-5_6

97. Zhang LN, Kong CF, Zhao D, Cong XL, Wang SS, Ma L, et al. Fusion With Mesenchymal Stem Cells Differentially Affects Tumorigenic and Metastatic Abilities of Lung Cancer Cells. J Cell Physiol (2019) 234:3570-82. doi: $10.1002 / j \mathrm{cp} .27011$

98. Balch C, Nephew KP, Huang THM, Bapat SA. Epigenetic "Bivalently Marked" Process of Cancer Stem Cell-Driven Tumorigenesis. BioEssays (2007) 29:842-5. doi: 10.1002/bies.20619

99. Feinberg AP. Phenotypic Plasticity and the Epigenetics of Human Disease. Nature (2007) 447:433-40. doi: 10.1038/nature05919

100. Jones PA, Baylin SB. The Epigenomics of Cancer. Cell (2007) 128:683-92. doi: 10.1016/j.cell.2007.01.029

101. Bjerkvig R, Tysnes BB, Aboody KS, Najbauer J, Terzis AJA. The Origin of the Cancer Stem Cell: Current Controversies and New Insights. Nat Rev Cancer (2005) 5:899-904. doi: 10.1038/nrc1740
102. Gupta PB, Chaffer CL, Weinberg RA. Cancer Stem Cells: Mirage or Reality? Nat Med (2009) 15:1010-2. doi: 10.1038/nm0909-1010

103. Pardal R, Clarke MF, Morrison SJ. Applying the Principles of Stem-Cell Biology to Cancer. Nat Rev Cancer (2003) 3:895-902. doi: 10.1038/nrc1232

104. Wicha MS, Liu S, Dontu G. Cancer Stem Cells: An Old Idea - A Paradigm Shift. Cancer Res (2006) 66:1883-90. doi: 10.1158/0008-5472.CAN-05-3153

105. Teng IW, Hou PC, Lee KD, Chu PY, Yeh KT, Jin VX, et al. Targeted Methylation of Two Tumor Suppressor Genes Is Sufficient to Transform Mesenchymal Stem Cells Into Cancer Stem/Initiating Cells. Cancer Res (2011) 71:4653-63. doi: 10.1158/0008-5472.CAN-10-3418

106. Teodoridis JM, Hall J, Marsh S, Kannall HD, Smyth C, Curto J, et al. CpG Island Methylation of DNA Damage Response Genes in Advanced Ovarian Cancer. Cancer Res (2005) 65:8961-7. doi: 10.1158/0008-5472.CAN-05-1187

107. Aggerholm A, Holm MS, Guldberg P, Olesen LH, Hokland P. Promoter Hypermethylation of P15ink4b, HIC1, CDH1, and ER Is Frequent in Myelodysplastic Syndrome and Predicts Poor Prognosis in Early-Stage Patients. Eur J Haematol (2006) 76:23-32. doi: 10.1111/j.1600-0609. 2005.00559.x

108. Chen WY, Cooper TK, Zahnow CA, Overholtzer M, Zhao Z, Ladanyi M, et al. Epigenetic and Genetic Loss of Hicl Function Accentuates the Role of P53 in Tumorigenesis. Cancer Cell (2004) 6:387-98. doi: 10.1016/ j.ccr.2004.08.030

109. Bao Q, Zhao Y, Niess H, Conrad C, Schwarz B, Jauch KW, et al. Mesenchymal Stem Cell-Based Tumor-Targeted Gene Therapy in Gastrointestinal Cancer. Stem Cells Dev (2012) 21:2355-63. doi: 10.1089/ scd.2012.0060

110. Gargett CE, Masuda H. Adult Stem Cells in the Endometrium. Mol Hum Reprod (2010) 16:818-34. doi: 10.1093/molehr/gaq061

111. Torsvik A, Bjerkvig R. Mesenchymal Stem Cell Signaling in Cancer Progression. Cancer Treat Rev (2013) 39:180-8. doi: 10.1016/j.ctrv. 2012.03.005

112. Riggi N, Suvà ML, De Vito C, Provero $\mathrm{P}$, Stehle JC, Baumer K, et al. EWSFLI-1 Modulates Mirna145 and SOX2 Expression to Initiate Mesenchymal Stem Cell Reprogramming Toward Ewing Sarcoma Cancer Stem Cells. Genes Dev (2010) 24:916-32. doi: 10.1101/gad.1899710

113. El-Badawy A, Ghoneim MA, Gabr MM, Salah RA, Mohamed IK, Amer M, et al. Cancer Cell-Soluble Factors Reprogram Mesenchymal Stromal Cells to Slow Cycling, Chemoresistant Cells With a More Stem-Like State. Stem Cell Res Ther (2017) 8:1-20. doi: 10.1186/s13287-017-0709-9

114. Timaner M, Letko-Khait N, Kotsofruk R, Benguigui M, Beyar-Katz O, Rachman-Tzemah C, et al. Therapy-Educated Mesenchymal Stem Cells Enrich for Tumor-Initiating Cells. Cancer Res (2018) 78:1253-65. doi: 10.1158/0008-5472.CAN-17-1547

115. Zhong H, Davis A, Ouzounova M, Carrasco RA, Chen C, Breen S, et al. A Novel IL6 Antibody Sensitizes Multiple Tumor Types to Chemotherapy Including Trastuzumab-Resistant Tumors. Cancer Res (2016) 76:480-90. doi: 10.1158/0008-5472.CAN-15-0883

116. Njatcha C, Farooqui M, Kornberg A, Johnson DE, Grandis JR, Siegfried JM. STAT3 Cyclic Decoy Demonstrates Robust Antitumor Effects in Non-Small Cell Lung Cancer. Mol Cancer Ther (2018) 17:1917-26. doi: 10.1158/15357163.MCT-17-1194

117. London B, Baker LC, Lee JS, Shusterman V, Choi BR, Kubota T, et al. Calcium-Dependent Arrhythmias in Transgenic Mice With Heart Failure. Am J Physiol Heart Circ Physiol (2003) 284:H431-41. doi: 10.1152/ ajpheart.00431.2002

118. Yen TWF, Aardal NP, Bronner MP, Thorning DR, Savard CE, Lee SP, et al. Myofibroblasts Are Responsible for the Desmoplastic Reaction Surrounding Human Pancreatic Carcinomas. Surgery (2002) 131:129-34. doi: 10.1067/ msy.2002.119192

119. Waghray M, Yalamanchili M, Magliano MPd, Simeone DM. Deciphering the Role of Stroma in Pancreatic Cancer. Curr Opin Gastroenterol (2013) 29:537-43. doi: 10.1097/MOG.0b013e328363affe

120. Olive KP, Jacobetz MA, Davidson CJ, Gopinathan A, McIntyre D, Honess D, et al. Inhibition of Hedgehog Signaling Enhances Delivery of Chemotherapy in a Mouse Model of Pancreatic Cancer. Science (80- ) (2009) 324:1457-61. doi: $10.1126 /$ science. 1171362

121. Chan TS, Shaked Y, Tsai KK. Targeting the Interplay Between Cancer Fibroblasts, Mesenchymal Stem Cells, and Cancer Stem Cells in 
Desmoplastic Cancers. Front Oncol (2019) 9:688. doi: 10.3389/fonc. 2019.00688

122. Polyak K, Weinberg RA. Transitions Between Epithelial and Mesenchymal States: Acquisition of Malignant and Stem Cell Traits. Nat Rev Cancer (2009) 9:265-73. doi: $10.1038 / \mathrm{nrc} 2620$

123. Su S, Chen J, Yao H, Liu J, Yu S, Lao L, et al. CD10+GPR77+ CancerAssociated Fibroblasts Promote Cancer Formation and Chemoresistance by Sustaining Cancer Stemness. Cell (2018) 172:841-856.e16. doi: 10.1016/ j.cell.2018.01.009

124. Loebinger MR, Eddaoudi A, Davies D, Janes SM. Mesenchymal Stem Cell Delivery of TRAIL can Eliminate Metastatic Cancer. Cancer Res (2009) 69:4134-42. doi: 10.1158/0008-5472.CAN-08-4698

125. Sasportas LS, Kasmieh R, Wakimoto H, Hingtgen S, Van De Water JAJM, Mohapatra G, et al. Assessment of Therapeutic Efficacy and Fate of Engineered Human Mesenchymal Stem Cells for Cancer Therapy. Proc Natl Acad Sci USA (2009) 106:4822-7. doi: 10.1073/pnas.0806647106

126. Naseri Z, Oskuee RK, forouzandeh-moghadam M, Jaafari MR. Delivery of LNA-antimiR-142-3p by Mesenchymal Stem Cells-Derived Exosomes to Breast Cancer Stem Cells Reduces Tumorigenicity. Stem Cell Rev Rep (2020) 16:541-56. doi: 10.1007/s12015-019-09944-w

127. Scherzed A, Hackenberg S, Froelich K, Kessler M, Koehler C, Hagen R, et al. BMSC Enhance the Survival of Paclitaxel Treated Squamous Cell Carcinoma Cells In Vitro. Cancer Biol Ther (2011) 11:349-57. doi: 10.4161/cbt.11.3.14179

128. Lis R, Touboul C, Mirshahi P, Ali F, Mathew S, Nolan DJ, et al. Tumor Associated Mesenchymal Stem Cells Protects Ovarian Cancer Cells From Hyperthermia Through CXCL12. Int J Cancer (2011) 128:715-25. doi: 10.1002/ijc.25619

129. Roodhart JML, Daenen LGM, Stigter ECA, Prins HJ, Gerrits J, Houthuijzen $\mathrm{JM}$, et al. Mesenchymal Stem Cells Induce Resistance to Chemotherapy Through the Release of Platinum-Induced Fatty Acids. Cancer Cell (2011) 20:370-83. doi: 10.1016/j.ccr.2011.08.010

130. Skolekova S, Matuskova M, Bohac M, Toro L, Demkova L, Gursky J, et al. Cisplatin-Induced Mesenchymal Stromal Cells-Mediated Mechanism Contributing to Decreased Antitumor Effect in Breast Cancer Cells. Cell Commun Signal (2016) 14:4. doi: 10.1186/s12964-016-0127-0

131. Poggi A, Varesano S, Zocchi MR. How to Hit Mesenchymal Stromal Cells and Make the Tumor Microenvironment Immunostimulant Rather Than Immunosuppressive. Front Immunol (2018) 9:262. doi: 10.3389/ fimmu.2018.00262

132. Liu C, Kelnar K, Liu B, Chen X, Calhoun-Davis T, Li H, et al. The microRNA miR-34a Inhibits Prostate Cancer Stem Cells and Metastasis by Directly Repressing CD44. Nat Med (2011) 17:211-6. doi: 10.1038/nm.2284

133. Li Y, Rogoff HA, Keates S, Gao Y, Murikipudi S, Mikule K, et al. Suppression of Cancer Relapse and Metastasis by Inhibiting Cancer Stemness. Proc Natl Acad Sci USA (2015) 112:1839-44. doi: 10.1073/pnas.1424171112

134. Liu S, Cong Y, Wang D, Sun Y, Deng L, Liu Y, et al. Breast Cancer Stem Cells Transition Between Epithelial and Mesenchymal States Reflective of Their Normal Counterparts. Stem Cell Rep (2014) 2:78-91. doi: 10.1016/ j.stemcr.2013.11.009

135. Stankic M, Pavlovic S, Chin Y, Brogi E, Padua D, Norton L, et al. TGF- $\beta$-Id1 Signaling Opposes Twist1 and Promotes Metastatic Colonization via a Mesenchymal-to-Epithelial Transition. Cell Rep (2013) 5:1228-42. doi: 10.1016/j.celrep.2013.11.014

136. Colacino JA, Azizi E, Brooks MD, Harouaka R, Fouladdel S, McDermott SP, et al. Heterogeneity of Human Breast Stem and Progenitor Cells as Revealed by Transcriptional Profiling. Stem Cell Rep (2018) 10:1596-609. doi: 10.1016/ j.stemcr.2018.03.001

137. Shimokawa M, Ohta Y, Nishikori S, Matano M, Takano A, Fujii M, et al. Visualization and Targeting of LGR5 + Human Colon Cancer Stem Cells. Nature (2017) 545:187-92. doi: 10.1038/nature22081

138. De Sousa E Melo F, Kurtova AV, Harnoss JM, Kljavin N, Hoeck JD, Hung J, et al. A Distinct Role for Lgr5 + Stem Cells in Primary and Metastatic Colon Cancer. Nature (2017) 543:676-80. doi: 10.1038/nature21713

139. Özdemir BC, Pentcheva-Hoang T, Carstens JL, Zheng X, Wu CC, Simpson TR, et al. Depletion of Carcinoma-Associated Fibroblasts and Fibrosis Induces Immunosuppression and Accelerates Pancreas Cancer With Reduced Survival. Cancer Cell (2014) 25:719-34. doi: 10.1016/j.ccr. 2014.04.005
140. Miao L, Liu Q, Lin CM, Luo C, Wang Y, Liu L, et al. Targeting TumorAssociated Fibroblasts for Therapeutic Delivery in Desmoplastic Tumors. Cancer Res (2017) 77:719-31. doi: 10.1158/0008-5472.CAN-16-0866

141. Miao L, Lin CM, Huang L. Stromal Barriers and Strategies for the Delivery of Nanomedicine to Desmoplastic Tumors. J Control Release (2015) 219:192204. doi: $10.1016 /$ j.jconrel.2015.08.017

142. Von Hoff DD, Ramanathan RK, Borad MJ, Laheru DA, Smith LS, Wood TE, et al. Gemcitabine Plus Nab-Paclitaxel is an Active Regimen in Patients With Advanced Pancreatic Cancer: A Phase I/II Trial. J Clin Oncol (2011) 29:4548-54. doi: 10.1200/JCO.2011.36.5742

143. Wang S, El-Deiry WS. TRAIL and Apoptosis Induction by TNF-Family Death Receptors. Oncogene (2003) 22:8628-33. doi: 10.1038/sj.onc.1207232

144. Fakiruddin KS, Ghazalli N, Lim MN, Zakaria Z, Abdullah S. Mesenchymal Stem Cell Expressing TRAIL as Targeted Therapy Against Sensitised Tumour. Int J Mol Sci (2018) 19:2188. doi: 10.3390/ijms19082188

145. Cafforio P, Viggiano L, Mannavola F, Pellè E, Caporusso C, Maiorano E, et al. PIL6-TRAIL-Engineered Umbilical Cord Mesenchymal/Stromal Stem Cells are Highly Cytotoxic for Myeloma Cells Both In Vitro and In Vivo. Stem Cell Res Ther (2017) 8:1-13. doi: 10.1186/s13287-017-0655-6

146. Han J, Hwang HS, Na K. TRAIL-Secreting Human Mesenchymal Stem Cells Engineered by a Non-Viral Vector and Photochemical Internalization for Pancreatic Cancer Gene Therapy. Biomaterials (2018) 182:259-68. doi: 10.1016/j.biomaterials.2018.08.024

147. Wiley SR, Schooley K, Smolak PJ, Din WS, Huang CP, Nicholl JK, et al. Identification and Characterization of a New Member of the TNF Family That Induces Apoptosis. Immunity (1995) 3:673-82. doi: 10.1016/1074-7613 (95) $90057-8$

148. Franco AV, Zhang XD, Van Berkel E, Sanders JE, Zhang XY, Thomas WD, et al. The Role of NF- $\mathrm{Kb}$ in TNF-Related Apoptosis-Inducing Ligand (TRAIL)-Induced Apoptosis of Melanoma Cells. J Immunol (2001) 166:5337-45. doi: 10.4049/jimmunol.166.9.5337

149. Sheridan JP, Marsters SA, Pitti RM, Gurney A, Skubatch M, Baldwin D, et al. Control of TRAIL-Induced Apoptosis by a Family of Signaling and Decoy Receptors. Science (80- ) (1997) 277:818-21. doi: 10.1126/science.277. 5327.818

150. Capper D, Gaiser T, Hartmann C, Habel A, Mueller W, Herold-Mende C, et al. Stem-Cell-Like Glioma Cells are Resistant to TRAIL/Apo2L and Exhibit Down-Regulation of Caspase- 8 by Promoter Methylation. Acta Neuropathol (2009) 117:445-56. doi: 10.1007/s00401-009-0494-3

151. Loebinger MR, Sage EK, Davies D, Janes SM. TRAIL-Expressing Mesenchymal Stem Cells Kill the Putative Cancer Stem Cell Population. Br J Cancer (2010) 103:1692-7. doi: 10.1038/sj.bjc.6605952

152. Fakiruddin KS, Lim MN, Nordin N, Rosli R, Zakaria Z, Abdullah S, Targeting of CD133+ Cancer Stem Cells by Mesenchymal Stem Cell Expressing TRAIL Reveals a Prospective Role of Apoptotic Gene Regulation in Non-Small Cell Lung Cancer. Cancers (Basel) (2019) 11:1261. doi: 10.3390/cancers11091261

153. Lee SH, Hyun SK, Kim HB, Kang CD, Kim SH. Potential Role of CD133 Expression in the Susceptibility of Human Liver Cancer Stem-Like Cells to TRAIL. Oncol Res (2016) 24:495-509. doi: 10.3727/096504016X14685034103950

154. Signore M, Ricci-Vitiani L, De Maria R. Targeting Apoptosis Pathways in Cancer Stem Cells. Cancer Lett (2013) 332:374-82. doi: 10.1016/j.canlet. 2011.01.013

155. Barr MP, Gray SG, Hoffmann AC, Hilger RA, Thomale J, O’Flaherty JD, et al. Generation and Characterisation of Cisplatin-Resistant Non-Small Cell Lung Cancer Cell Lines Displaying a Stem-Like Signature. PloS One (2013) 8: e54193. doi: 10.1371/journal.pone.0054193

156. Shimono Y, Zabala M, Cho RW, Lobo N, Dalerba P, Qian D, et al. Downregulation of miRNA-200c Links Breast Cancer Stem Cells With Normal Stem Cells. Cell (2009) 138:592-603. doi: 10.1016/j.cell.2009.07.011

157. Isobe T, Hisamori S, Hogan DJ, Zabala M, Hendrickson DG, Dalerba P, et al. miR-142 Regulates the Tumorigenicity of Human Breast Cancer Stem Cells Through the Canonical WNT Signaling Pathway. Elife (2014) 3:e01977. doi: 10.7554/eLife.01977

158. Sundaram B, Herbert FJ, Kumar S. Human Mesenchymal Stem Cell (hMSC) - Derived Exosomes/Exosome Mimetics as a Potential Novel Therapeutic Tool for Regenerative Medicine. Springer, Singapore: Regenerative Medicine: Laboratory to Clinic (2017). p. 81-97. doi: 10.1007/978-981-10-3701-6_5 
159. Mohsenzadegan M, Peng R, Roudi R. Dendritic Cell/Cytokine-Induced Killer Cell-Based Immunotherapy in Lung Cancer: What We Know and Future Landscape. J Cell Physiol (2020) 235:74-86. doi: 10.1002/jcp.28977

160. Hass R, Kasper C, Böhm S, Jacobs R. Different Populations and Sources of Human Mesenchymal Stem Cells (MSC): A Comparison of Adult and Neonatal Tissue-Derived MSC. Cell Commun Signal (2011) 9:1-14. doi: 10.1186/1478-811X-9-12

161. Shi Y, Wang Y, Li Q, Liu K, Hou J, Shao C, et al. Immunoregulatory Mechanisms of Mesenchymal Stem and Stromal Cells in Inflammatory Diseases. Nat Rev Nephrol (2018) 14:493-507. doi: 10.1038/s41581-018-0023-5

162. Juneja SC, Viswanathan S, Ganguly M, Veillette C. A Simplified Method for the Aspiration of Bone Marrow From Patients Undergoing Hip and Knee Joint Replacement for Isolating Mesenchymal Stem Cells and In Vitro Chondrogenesis. Bone Marrow Res (2016) 2016:1-18. doi: 10.1155/2016/ 3152065

163. Yin JQ, Zhu J, Ankrum JA. Manufacturing of Primed Mesenchymal Stromal Cells for Therapy. Nat BioMed Eng (2019) 3:90-104. doi: 10.1038/s41551018-0325-8

164. Wilson JG, Liu KD, Zhuo H, Caballero L, McMillan M, Fang X, et al. Mesenchymal Stem (Stromal) Cells for Treatment of ARDS: A Phase 1 Clinical Trial. Lancet Respir Med (2015) 3:24-32. doi: 10.1016/S2213-2600 (14)70291-7

165. François M, Copland IB, Yuan S, Romieu-Mourez R, Waller EK, Galipeau J. Cryopreserved Mesenchymal Stromal Cells Display Impaired Immunosuppressive Properties as a Result of Heat-Shock Response and Impaired Interferon- $\gamma$ Licensing. Cytotherapy (2012) 14:147-52. doi: 10.3109/14653249.2011.623691

166. Antunes MA, Abreu SC, Cruz FF, Teixeira AC, Lopes-Pacheco M, Bandeira E, et al. Effects of Different Mesenchymal Stromal Cell Sources and Delivery
Routes in Experimental Emphysema. Respir Res (2014) 15:1-14. doi: 10.1186/ s12931-014-0118-x

167. O'Cearbhaill ED, Ng KS, Karp JM. Emerging Medical Devices for Minimally Invasive Cell Therapy. Mayo Clin Proc (2014) 89:259-73. doi: 10.1016/ j.mayocp.2013.10.020

168. Wang Y, Chen X, Cao W, Shi Y. Plasticity of Mesenchymal Stem Cells in Immunomodulation: Pathological and Therapeutic Implications. Nat Immunol (2014) 15:1009-16. doi: 10.1038/ni.3002

169. Hess DC, Wechsler LR, Clark WM, Savitz SI, Ford GA, Chiu D, et al. Safety and Efficacy of Multipotent Adult Progenitor Cells in Acute Ischaemic Stroke (MASTERS): A Randomised, Double-Blind, Placebo-Controlled, Phase 2 Trial. Lancet Neurol (2017) 16:360-8. doi: 10.1016/S1474-4422(17)30046-7

Conflict of Interest: The authors declare that the research was conducted in the absence of any commercial or financial relationships that could be construed as a potential conflict of interest.

Publisher's Note: All claims expressed in this article are solely those of the authors and do not necessarily represent those of their affiliated organizations, or those of the publisher, the editors and the reviewers. Any product that may be evaluated in this article, or claim that may be made by its manufacturer, is not guaranteed or endorsed by the publisher.

Copyright (c) 2022 Jing, Liang, Zhang, Tang and Huang. This is an open-access article distributed under the terms of the Creative Commons Attribution License (CC BY). The use, distribution or reproduction in other forums is permitted, provided the original author(s) and the copyright owner(s) are credited and that the original publication in this journal is cited, in accordance with accepted academic practice. No use, distribution or reproduction is permitted which does not comply with these terms. 


\section{GLOSSARY}

\begin{tabular}{|c|c|}
\hline$A R$ & androgen receptor \\
\hline BCSCs & breast cancer stem cells \\
\hline BM-MSCs & bone marrow mesenchymal stromal cells \\
\hline $\mathrm{BMP}$ & bone morphogenetic protein \\
\hline CAFs & cancer-associated fibroblasts \\
\hline CA-MSCs & cancer associated MSCs \\
\hline CCL5 & c-c motif chemokine ligand 5 \\
\hline$C D$ & cluster of differentiation \\
\hline COX-2 & cyclooxygenase-2 \\
\hline $\mathrm{CRC}$ & colorectal cancer \\
\hline CSCs & cancer stem cells \\
\hline $\mathrm{CXCL}$ & chemokine ( $\mathrm{C}-\mathrm{X}-\mathrm{C}$ motif) ligand \\
\hline CXCR & CXC chemokine receptors \\
\hline DNA & deoxyribonucleic acid \\
\hline DR & death receptor \\
\hline ECM & extracellular matrix \\
\hline EGF & epidermal growth factor \\
\hline EMT & epithelial-mesenchymal transition \\
\hline ERK & extracellular signal-regulated kinase \\
\hline EVs & extracellular vesicles \\
\hline EWS & ewings sarcoma \\
\hline FAK & focal adhesion kinase \\
\hline gCSCs & glioma cancer stem cells \\
\hline GP130 & glycoprotein 130 \\
\hline GPR-77 & G protein-coupled receptor 77 \\
\hline GRO- $\alpha$ & growth-regulated oncogene- $\alpha$ \\
\hline HGF & hepatocyte growth factor \\
\hline HNSCC & head and neck squamous cell carcinoma \\
\hline $\mathrm{IFN} \gamma$ & interferon $\gamma$ \\
\hline IGF & insulin-like growth factor 1 \\
\hline IL & interleukin \\
\hline IL-6R & interleukin 6 receptor \\
\hline LDM & low-dose metronomic \\
\hline LGR-5 & leucine-rich repeat-containing G-protein coupled receptor 5 \\
\hline LNA & locked nucleic acid \\
\hline MCs & mesenchymal cells \\
\hline miRNAs & microRNAs \\
\hline MMP & matrix metallopeptidase \\
\hline mPGES-1 & microsomal Prostaglandin-E synthase-1 \\
\hline MPO & myeloperoxidase \\
\hline MSCs & mesenchymal stem cells \\
\hline mTOR & mammalian target of rapamycin \\
\hline$N F-\kappa B$ & nuclear factor kappa B \\
\hline NO & nitric oxide \\
\hline NOD/SCID & nonobese diabetic/severe combined immunodeficiency \\
\hline NSCLC & non-small cell lung carcinoma \\
\hline OPN & osteopontin \\
\hline $\mathrm{PCa}$ & prostate cancer \\
\hline PDAC & pancreatic ductal adenocarcinoma \\
\hline PDGF & platelet-derived growth factor \\
\hline PGE-2 & prostaglandin-E2 \\
\hline SDF-1 & stromal cell-derived factor 1 \\
\hline SP & side population \\
\hline SSM & stem/serrated/mesenchymal \\
\hline STAT & signal transducers and activators of transcription \\
\hline TGF- $\beta$ & transforming growth factor- $\beta$ \\
\hline TNF- $\alpha$ & tumor necrosis factor- $\alpha$ \\
\hline TRAIL & TNF-related apoptosis inducing ligand \\
\hline WJMSC & Wharton's jelly of umbilical cord \\
\hline
\end{tabular}

